\section{RATIONALIZATION OF PRODUCTION OF SHAPED INSERTS FOR ROTOR CASTING}

PAVEL DOSTAL, MAREK SADILEK

Faculty of Mechanical Engineering, Department of machining, assembly and engineering metrology

VSB-TU Ostrava, Czech republic

DOI: 10.17973/MMSJ.2021_10_2021088

Email: dostal.pa@email.cz The article deals with the rationalization of the production of shaped inserts for casting rotors. The theoretical part describes the characteristics of shaped inserts for rotor casting, die casting technology, analysis of the existing technology of production of shaped inserts. The main part of the article is focused on the proposed technological process of production, comparison of existing and proposed process. The article concludes with a technical and economic benefit of the proposed solution and evaluation of the work. Rationalization of production has its justification in the development of the company and thus improve competitiveness in the market. These interventions in production offer the possibility of using new technologies that are beneficial both from an economic point of view and to improve working conditions. The article focuses on the description of the existing technology, its evaluation and subsequent processing of a new technological process.

KEYWORDS

Rationalization, die casting, shaped inserts, casting, milling

\section{INTRODUCTION}

Shaped inserts for rotor casting (hereinafter only inserts) are always produced in two versions, one front and one rear. They are used for axial heights numbered 100,112, 132 and 160 After production in the tool shop, the insert is put into diecasting operation. Here it is inserted into a device for highpressure aluminum casting. Multiple inserts can be stacked in the die at the same time according to the axial height. As already mentioned, the insert consists of two parts. We can divide them into fixed and movable. The fixed part is clamped on the table and there may be an inlet. On the contrary, the movable part is clamped on the mold carrier, where the mechanism for releasing the casting is located.

\section{THE PROCESS OF MANUFACTURING SHAPED INSERTS}

The process can be divided into several phases. The customer requires certain term, price and technical requirements that must be met or agreed upon. These requirements result in a drawing or 3D model. This documentation contains dimensions, tolerances and acceptance conditions. If the castings are machined, not only is the documentation for the casting sufficient, but must also be supplied for the finished product. In the next step we can include the design of molds and tools for processing, material security, project plan, etc. An integral part is the processing of clamps, separate construction of the insert, construction of inspection jigs and tools. Emphasis should be placed on the production of the insert in such a quality that it does not have to be tested. The production of injection molds is a highly valued branch of today's engineering. A large number of molds are produced from tool steels by machining or electroerosive machining, but molds are also being produced by other technologies such as electroforming. Probably the largest share of all technologies is machining by milling. Constant pressure to reduce machine times and production costs leads to the development of milling methods and the use of eg high-speed machining (HSC), machining of very hard materials or dry machining, as well as the use of modern 5-axis machining centers. Current trends in machining lead to increased cutting speeds, removal of larger volumes of material, often without the presence of any process fluid. In addition to a machine tool capable of achieving the required cutting speed, rigidity and secure clamping, it is necessary have a specially designed tool. The mold test is performed in order to capture the parameters of casting from a technological point of view, as well as the dimensions, parameters of castings and, last but not least, to check the alloy used. During the process, it is important to optimize the insert according to the design agreed with the designer, tool shop and foundry. Data processing for zero series. The last step is the second test or production of the zero series. We verify inspection and production operations here. We emphasize the preparation of samples with a protocol, which is sent to the customer together with documents for serial production. [Grov 2005]

\section{PROPERTIES OF SHAPED INSERTS FOR CASTING ROTORS}

The material for the production of all types of shaped inserts was chosen according to the standard, CSN 19 552.3. The standard states that it is a medium alloy chromiummolybdenum tool steel. Requirements for the mold material used, good machinability, good hardenability, high yield strength, good thermal conductivity, low thermal expansion, adhesion resistance, dimensional stability during heat treatment. [Dostal 2012]
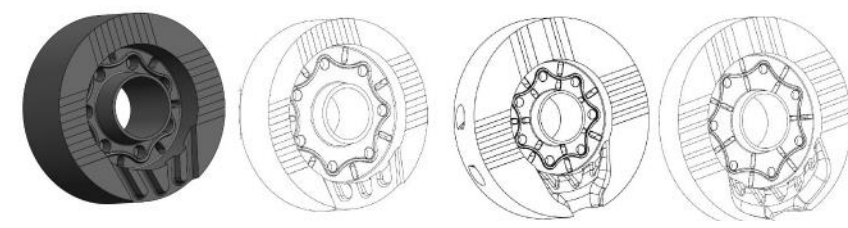

Figure 1. Solved shaped inserts [Dostal 2012]

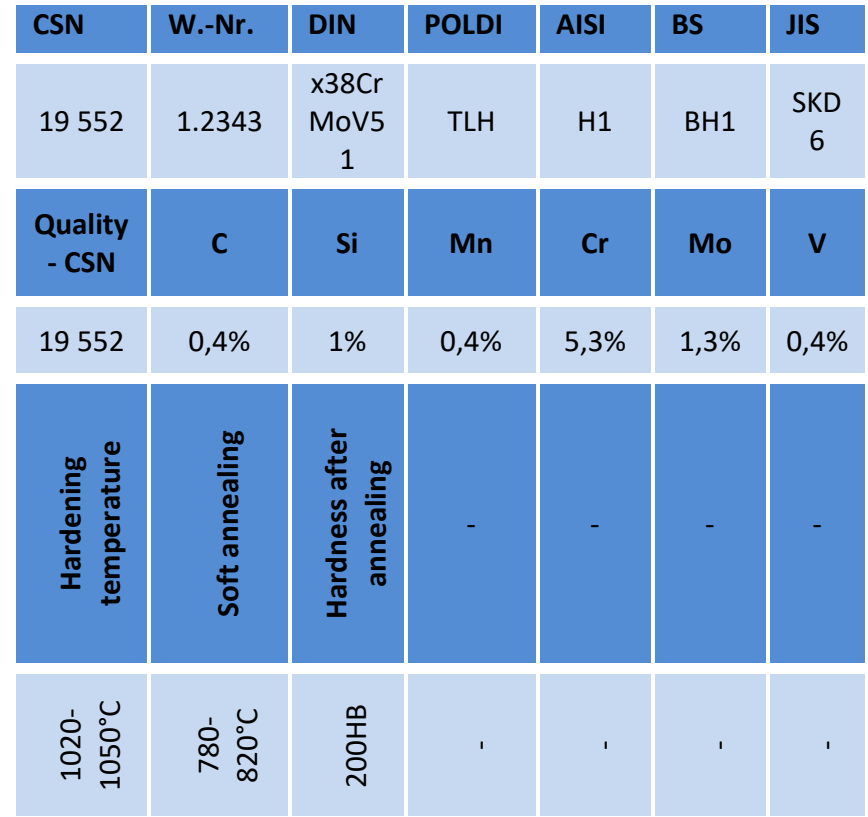

Table 1. Material for the production of shaped inserts [Lentus 2007] 
4 MACHINERY AND DESCRIPTION OF WORKPLACES FOR THE PRODUCTION OF SHAPED INSERTS

In this chapter I deal with the description of individual machines used in the current production of shaped inserts. Workplaces in technological procedures are marked with codes, all axial heights that I solve have the same workplace designations, they differ only in the tools and parameters used. I will also use most of the machinery in new technological processes with changes that meet the new criteria. [Dostal 2012]

Workplace VN0411 - lathe: uses model SV 18R from the manufacturer TOS Kurim. [Svoboda 2016]

Workplace VN0171 - hardener: vacuum furnace RDVA: twochamber, maximum charge size is $550 \times 370 \times 300 \mathrm{~mm}$, charge weight $100 \mathrm{~kg}$, maximum temperature $1020^{\circ} \mathrm{C}$. [Dostal 2012]

Workplace VN0471 - coordinate drilling machine manufacturer SIP: axis travel $\times 900 \mathrm{~mm}$, y axis travel $700 \mathrm{~mm}$, axis travel from $720 \mathrm{~mm}$, table dimensions $1100 \times 800 \mathrm{~mm}$. [Dostal 2012]

Workplace VN0564 - surface grinder BRH 50: machine manufacturer VOJUS. [Svoboda 2016]

Workplace VN0551 - circular grinder BU28 / 630: manufacturer TOS Melnik, maximum grinding diameter $295 \mathrm{~mm}$, maximum grinding length $630 \mathrm{~mm}$, maximum workpiece weight $60 \mathrm{~kg}$, power of the main electric motor $4 \mathrm{~kW}$, dimensions $2000 \times 1450 \mathrm{~mm}$, weight $2450 \mathrm{~kg}$. [Dostal 2012]

Workplace VN0596 - AGIE Compact 3 electroerosive dredging: table length $800 \mathrm{~mm}$, table width $600 \mathrm{~mm}$. [Dostal 2012]

Workplace VN0561 - surface grinder BPH 320A: manufacturer TOS Holice, table clamping surface $320 \times 1000 \mathrm{~mm}$. [Dostal 2012]

\section{EXISTING TECHNOLOGY FOR THE PRODUCTION OF SHAPED INSERTS}

For an example of rationalization, I will show the design of a front insert of axial height 160 . The material of the insert is medium-alloy chromium-molybdenum tool steel 19552.3. This insert is the largest of the solved inserts, the maximum diameter is $232 \mathrm{~mm}$, the diameter of the inner hole is $61 \mathrm{~mm}$ and the width is $50 \mathrm{~mm}$. The process of manufacturing a shaped insert is shown in Table 2. [Dostal 2012]

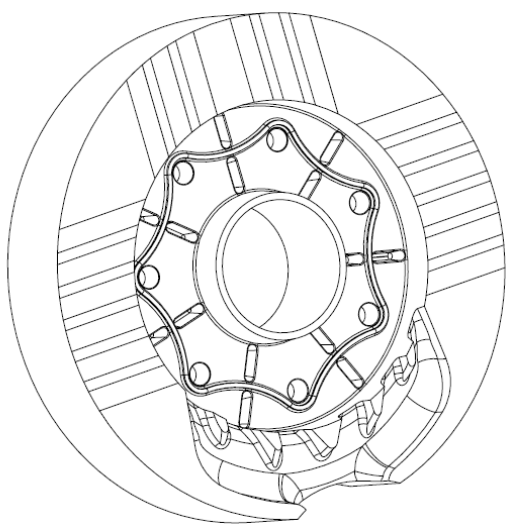

Figure 2. Shaped insert model [Dostal 2012]
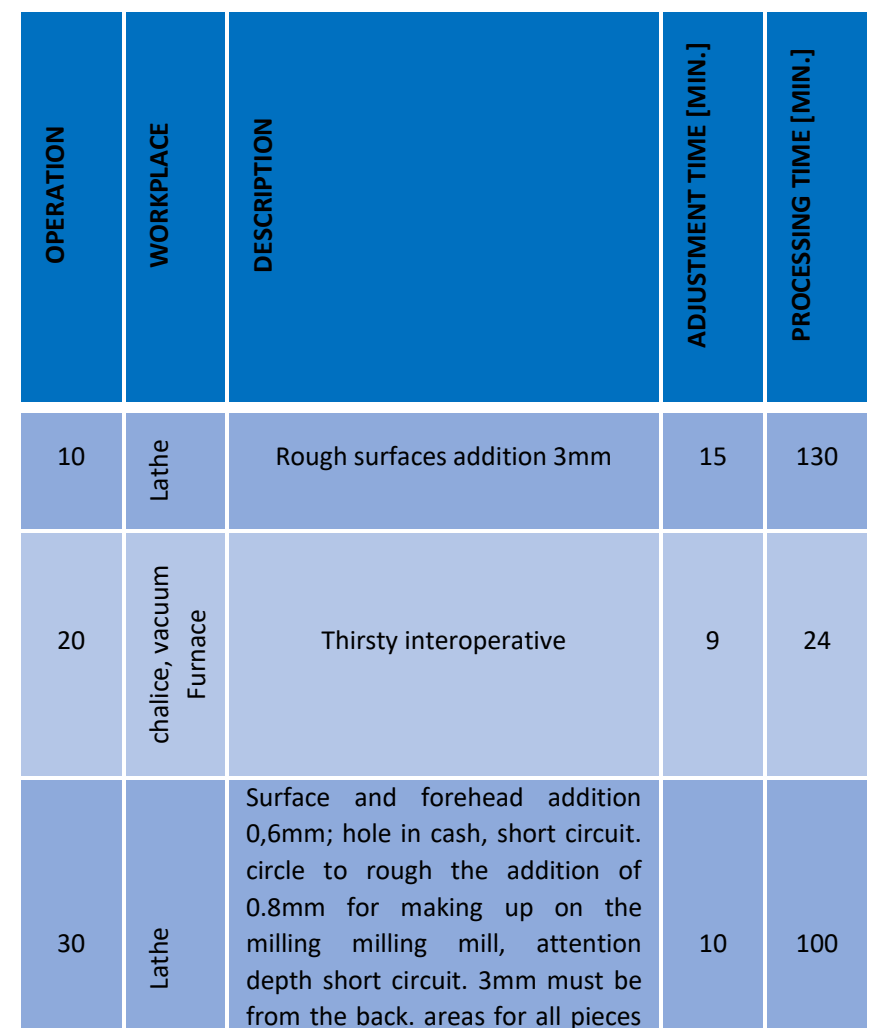
Surface and forehead addition
$0,6 \mathrm{~mm}$; hole in cash, short circuit
circle to rough the addition of
$0.8 \mathrm{~mm}$ for making up on the
milling milling mill, attention
depth short circuit. $3 \mathrm{~mm}$ must be
from the back. areas for all piece
are the same with regard to the
addition on the foreheads

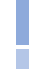

\begin{tabular}{|c|c|c|c|c|}
\hline & & & & \\
\hline 40 & 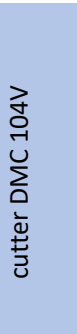 & $\begin{array}{l}\text { Bottom short circuit. circle with } \\
\text { the addition of } 0,5 \mathrm{~mm} \text {; rough } \\
\text { holes for balancing pins, make a } \\
\text { gate channel, drill for threads and } \\
2 x \text { Q } 10+0.03 \mathrm{~mm} \text {; rough } Q 110 \mathrm{~h} 7 \text {; } \\
\text { make grooves of the gate, rough } \\
\text { for hl. } 14 \mathrm{x} \text { groove of blades, } \\
\text { groove for marking to a depth of } \\
0.5 \mathrm{~mm} \text { in cash }\end{array}$ & 75 & 625 \\
\hline 50 & $\begin{array}{l}\frac{u}{c} \\
\frac{U}{0} \\
\frac{C}{U} \\
\stackrel{d}{z}\end{array}$ & $\begin{array}{l}\text { Cut threads, mark, edit, polish } \\
\text { inlet, prepare for hardening }\end{array}$ & 0 & 450 \\
\hline 60 & 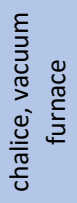 & Harden to $48 \mathrm{HRc}$ & 9 & 15 \\
\hline 70 & $\begin{array}{l}\frac{\grave{0}}{0} \\
\frac{.}{\frac{1}{2}} \\
\frac{0}{0} \\
\frac{\pi}{4}\end{array}$ & $\begin{array}{l}\text { Face to plane and tailored } \\
(50+0.02) \mathrm{mm} \text { according to } \\
\text { drawing, beware of blade depth }\end{array}$ & 9 & 45 \\
\hline 80 & $\begin{array}{l}\stackrel{0}{c} \\
\underset{T}{\pi} \\
\frac{\pi}{n}\end{array}$ & Clean hole & 15 & 12 \\
\hline 90 & 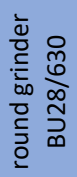 & Surface in cash & 15 & 39 \\
\hline
\end{tabular}




\begin{tabular}{|c|c|c|c|c|}
\hline 100 & 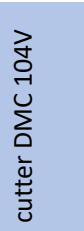 & $\begin{array}{l}\text { Shorting. circle and holes for } \\
\text { balancing pins in cash according to } \\
\text { the drawing, } \otimes 110 \mathrm{~h} 7 \text { in cash } \\
\text { according to the drawing, drawing } \\
\text { the islets of vent grooves for the } \\
\text { grinder }\end{array}$ & 60 & 210 \\
\hline 110 & 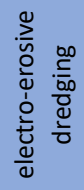 & $\begin{array}{c}\text { Blades in cash according to the } \\
\text { drawing }\end{array}$ & 60 & 540 \\
\hline 120 & 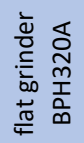 & Vent grooves in cash & 18 & 36 \\
\hline 130 & 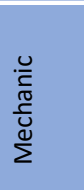 & $\begin{array}{l}\text { Make up after milling R0. } 3 \text { at the } \\
\text { hole and R0.5 at the groove, de- } \\
\text { eject, demagnetize, polish, } \\
\text { necessary to adjust, prepare for } \\
\text { hardening }\end{array}$ & 0 & 120 \\
\hline 140 & 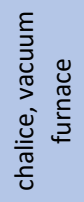 & $\begin{array}{l}\text { Paint with metalstar, put in a } \\
\text { furnace at } 300^{\circ} \mathrm{C}\end{array}$ & 9 & 30 \\
\hline 150 & 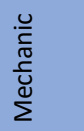 & $\begin{array}{l}\text { Check after quenching, clean after } \\
\text { quenching as needed, conserve }\end{array}$ & 0 & 21 \\
\hline
\end{tabular}

Table 2. General technological process of production of shaped insert [Havranek 2010]

The output of the existing technology is that the adjustment times are 304 minutes, the production times are 2397 minutes and the production price is CZK 20,864 . These parameters do not meet production requirements and slow down production. The product goes through 15 operations, which slow down and make production more expensive. Production capacity is not enough for the next necessary production. Electro-erosive gouging is used to machine the shaped insert. This item puts the most strain on the whole process and therefore a more advantageous alternative is being sought.

\section{COMPARISON OF ELECTROEROSIVE GOUGING AND HARD MILLING}

Electro-erosive gouging and hard milling are two production methods that are currently used in the production of molds and dies from hardened tool steels. By hard milling we mean highspeed machining (HSC high speed cutting) of steels with hardness over 56 HRC or strength over $2000 \mathrm{~N} / \mathrm{mm} 2$. Both production processes have their advantages and disadvantages, which play a role in choosing a more suitable method for a particular application. Of course, it is also possible to use both countersinking and hard milling for the production of one part, where the advantages of one method compensate for the disadvantages of the other method. [Alam], [Zelinski 2000], [Oettle 2005]

EDM is a very slow process. The main advantage of milling over dredging is therefore higher material removal and thus shorter machine times. One of the main criteria when choosing a machining method is the geometry of the final workpiece. Hard milling cannot achieve sharp inner corners and complex shapes that are difficult to achieve with the cutter. Dredging is also more suitable and often the only option for creating thin deep elements such as ribs, the thickness of which is $0.8-3 \mathrm{~mm}$ for small and medium-sized molds and their length is five to ten times their width. EDM machining is usually chosen for more complex workpieces with a number of small elements and details. As already mentioned, the machining process can be optimized by involving both methods. Large pockets and simpler parts can be milled and details subsequently added by EDM. [Alam], [Zelinski 2000], [Oettle 2005]

Other criteria that may influence the choice of a suitable machining method are the surface quality and the resulting accuracy. Hard milling is usually followed by polishing if a polished surface is required, while with EDM it is possible to achieve a surface corresponding to polishing directly, for example when using suspensions instead of pure dielectric. On the other hand, after excavation, a heat-affected zone and a white layer remain on the surface, which may be unacceptable for some applications. It is easier to observe the prescribed tolerances for milling than for countersinking, where inaccuracies are added from the electrode machining and from the countersinking itself, for which we must take into account the interelectrode distance. When digging, the accuracy also decreases with increasing surface quality and we must therefore balance the resulting surface with the required accuracy. Generally speaking, for components that can be manufactured in the required parameters by both methods, the one that is more available and cheaper in a specific case will be chosen. [Alam], [Zelinski 2000], [Oettle 2005]

There are other methods of machining shaped inserts on the market, but the workshop's machinery has made it possible to use comparisons only for electro-erosive gouging and milling. Other methods could not be verified in practice. I will only briefly mention here some other possibilities for the production of shaped inserts. In addition to CNC milling and electroerosive gouging, we can also use the methods of electroplating, electrospark machining - cutting, production of shaped parts of the mold by cold injection and more.

7 USE OF THE TAJMAC 1260 MACHINE FOR A NEW TECHNOLOGY FOR THE PRODUCTION OF SHAPED INSERTS

When designing a new technological process, I will focus on the use of machines with a continuously controlled 4-axis, which are the most advantageous for shape milling, for the needs of faster and better production I will use the TAJMAC machine. [TAJMAC-ZPS 2012] 


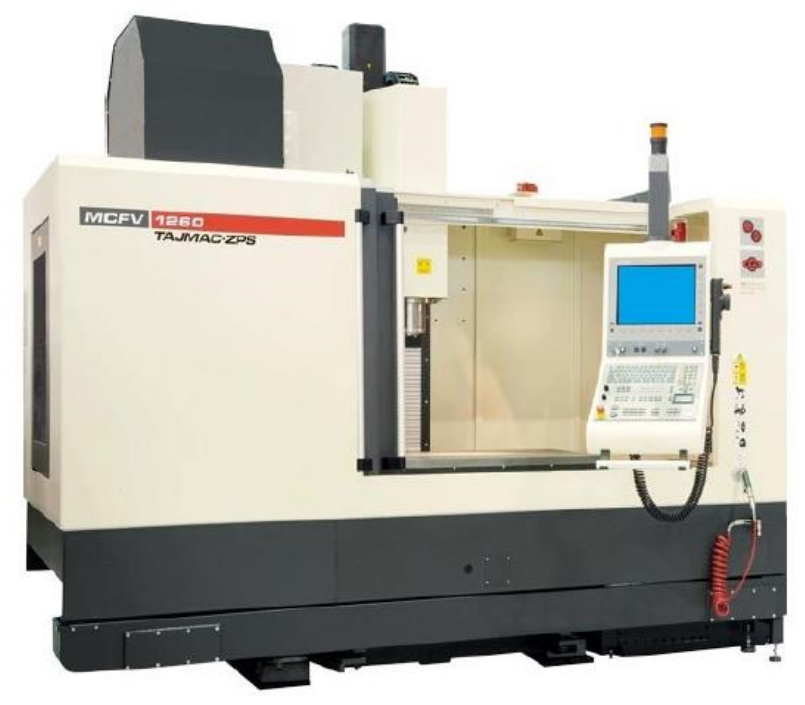

8 DESIGN OF A NEW TECHNOLOGY FOR THE PRODUCTION OF SHAPED INSERTS FOR CASTING ROTORS

In the previous chapter, I dealt with the current process of production of shaped inserts. In this chapter I will focus on a new technological process of production of individual shaped inserts. The drawings and dimensions of the individual parts do not change, I will only use other technologies for processing. Newly, in order to shorten production and adjustment times, 1 will use thermal clamping of tools, a calibration probe, etc. The current production technology is most burdened by machining complex insert shapes. I will therefore focus on the use of the production of complex shaped parts by milling. To distinguish between existing and new production technology, I will mark the new technology with the help of index $n$.

\begin{tabular}{|c|c|c|c|c|}
\hline $\begin{array}{l}z \\
\text { o } \\
\frac{1}{4} \\
\text { ü } \\
0\end{array}$ & WORKPLACE & DESCRIPTION & 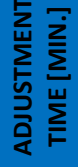 & 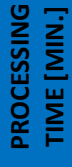 \\
\hline \multirow{6}{*}{10} & \multirow{6}{*}{$\begin{array}{l}\text { LATHE } \\
\text { SV18R }\end{array}$} & Turning - roughing: & \multirow{6}{*}{15} & \multirow{6}{*}{130} \\
\hline & & $\begin{array}{l}\text { 1. machine the forehead } \\
\text { addition } 3 \mathrm{~mm}\end{array}$ & & \\
\hline & & $\begin{array}{l}\text { 2. machine the diameter of } \\
\text { the addition } 3 \mathrm{~mm}\end{array}$ & & \\
\hline & & Rotate Workpiece & & \\
\hline & & $\begin{array}{l}\text { 3. machine the forehead } \\
\text { addition } 3 \mathrm{~mm}\end{array}$ & & \\
\hline & & $\begin{array}{l}\text { 4. machine the diameter of } \\
\text { the addition } 3 \mathrm{~mm}\end{array}$ & & \\
\hline 20 & $\begin{array}{l}\text { chalice, } \\
\text { vacuum } \\
\text { furnace }\end{array}$ & Thirsty interoperative & 9 & 24 \\
\hline \multirow{2}{*}{30.1} & \multirow{2}{*}{$\begin{array}{c}\text { milling } \\
\text { cutter MCFV } \\
1260\end{array}$} & $\begin{array}{l}\text { Milling faces } \\
\text { 1. Front addition } 0.6 \mathrm{~mm}\end{array}$ & \multirow{2}{*}{75} & \multirow{2}{*}{70} \\
\hline & & $\begin{array}{l}\text { 2. Surface with addition of } \\
0.6 \mathrm{~mm}\end{array}$ & & \\
\hline
\end{tabular}

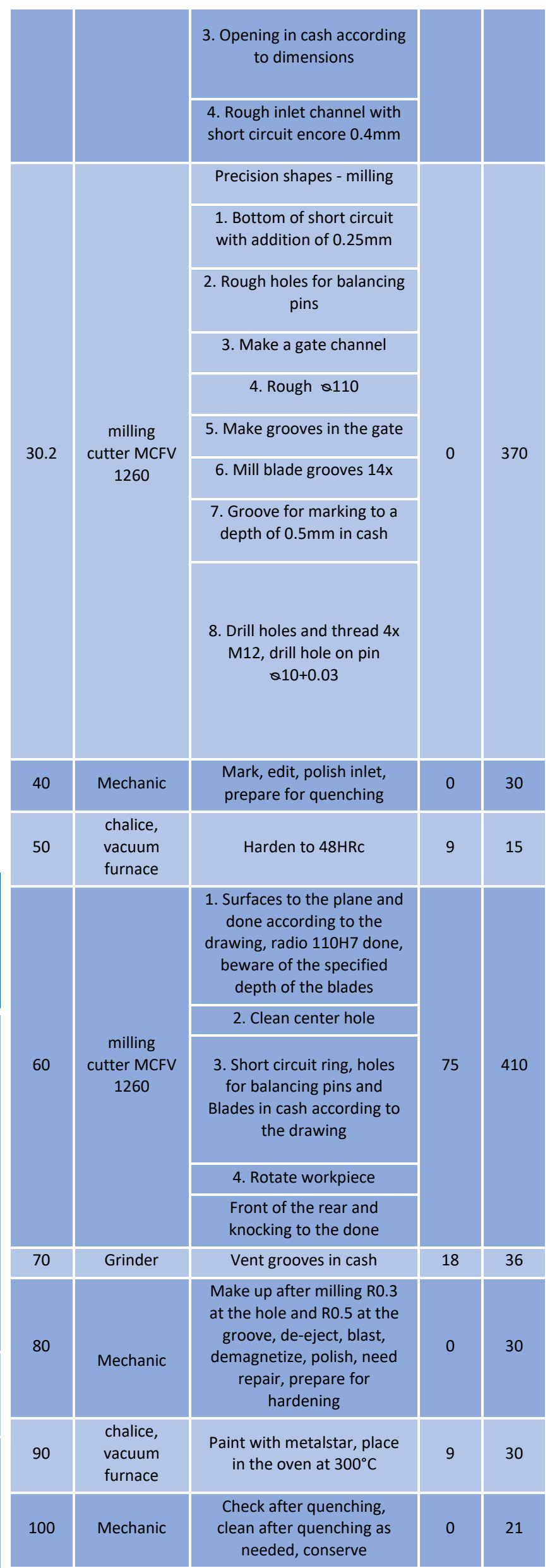

Table 3. General proposed technological procedure of the insert [Dostal 2012] 


\section{COMPARISON OF SHAPED INSERT TECHNOLOGY}

The insert is the largest of all types. Thanks to the identical shapes with the previous inserts, universal programs with tool changes can be used. The current technological process used electroerosive machining, which significantly extended production times. The proposed technological procedure mainly uses milling, this change is reflected in the total times, which have been shortened by several hours, as can be seen in the Table. Operation 30th turning is replaced by milling, this change was also applied to operations 70 to 110 .

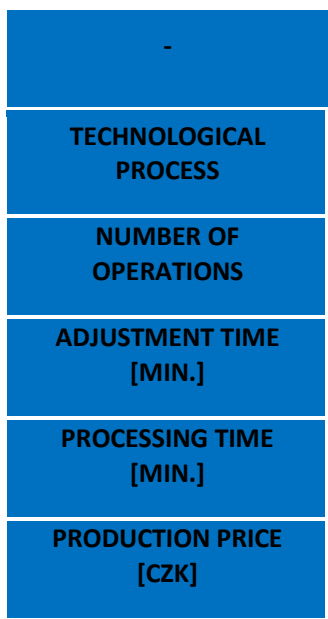

\begin{tabular}{|c|c|}
\hline $\begin{array}{c}\text { EXISTING } \\
\text { TECHNOLOGY }\end{array}$ & $\begin{array}{c}\text { PROPOSED } \\
\text { TECHNOLOGY }\end{array}$ \\
\hline Chapter 5 & Chapter 6 \\
\hline 15. & 10. \\
\hline 304 & 210 \\
\hline 2397 & 1166 \\
\hline 20864,17 & 11696,81 \\
\hline
\end{tabular}

Table 4. General proposed technological procedure of the insert [Dostal 2012]

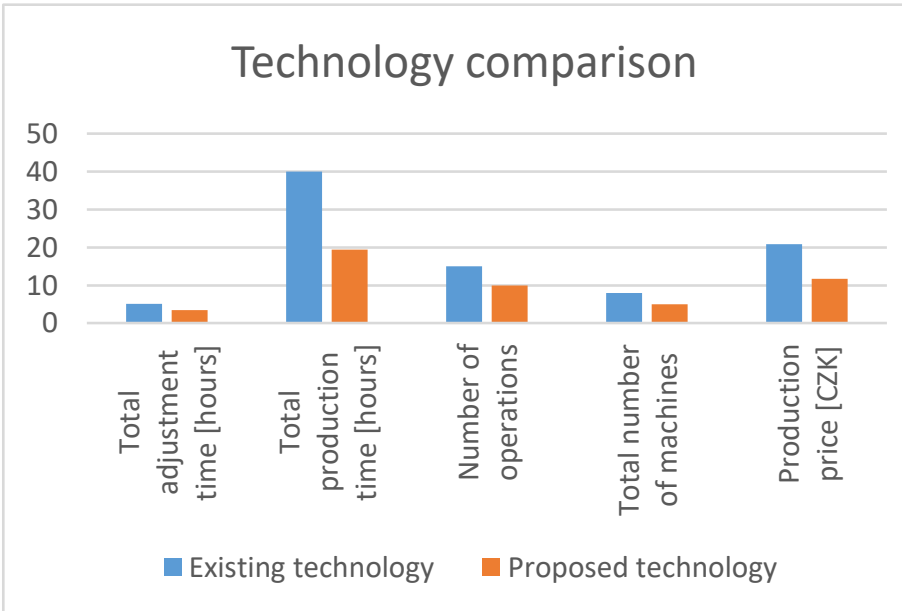

Chart 1. Technology comparison [Dostal 2012]

\section{ANOTHER PROPOSED SOLUTION FOR INSERTS OF OTHER AXIAL HEIGHTS}

The research addressed several axial heights for various shaped inserts. In this chapter I will only summarize the obtained data and a comparison of existing and proposed technologies for individual axle heights. Comparison with other methods of manufacturing shaped inserts was not possible due to limited machinery.

\begin{tabular}{|c|c|c|c|c|c|c|c|c|}
\hline \multirow{2}{*}{ 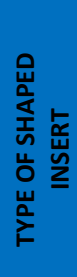 } & \multicolumn{2}{|c|}{$\begin{array}{l}\text { NUMBER OF } \\
\text { OPERATIONS }\end{array}$} & \multicolumn{2}{|c|}{$\begin{array}{l}\text { ADJUSTMENT } \\
\text { TIME [MIN.] }\end{array}$} & \multicolumn{2}{|c|}{$\begin{array}{l}\text { PROCESSING } \\
\text { TIME [MIN.] }\end{array}$} & \multicolumn{2}{|c|}{$\begin{array}{c}\text { PRODUCTION } \\
\text { PRICE [CZK] }\end{array}$} \\
\hline & 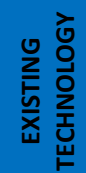 & 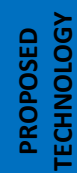 & 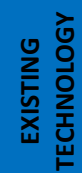 & 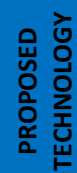 & 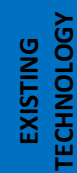 & 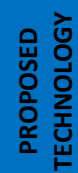 & 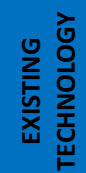 & 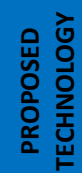 \\
\hline $\begin{array}{l}100 \\
\text { front }\end{array}$ & 15. & 10. & 210 & 163 & 1098 & 585 & 9804 & 5379 \\
\hline $\begin{array}{l}100 \\
\text { rear }\end{array}$ & 15. & 11. & 126 & 117 & 950 & 737 & 8310 & 6256 \\
\hline $\begin{array}{l}112 \\
\text { front }\end{array}$ & 15. & 9. & 201 & 156 & 995 & 616 & 7279 & 6033 \\
\hline $\begin{array}{l}112 \\
\text { rear }\end{array}$ & 16. & 11. & 165 & 162 & 909 & 687 & 6919 & 6668 \\
\hline $\begin{array}{l}132 \\
\text { front }\end{array}$ & 16. & 11. & 138 & 69 & 1613 & 1209 & 16471 & 11371 \\
\hline $\begin{array}{l}132 \\
\text { rear }\end{array}$ & 17. & 11. & 282 & 177 & 1287 & 816 & 8102 & 8201 \\
\hline $\begin{array}{l}160 \\
\text { front }\end{array}$ & 15. & 10. & 304 & 210 & 2397 & 1166 & 20864 & 11696 \\
\hline $\begin{array}{l}160 \\
\text { rear }\end{array}$ & 16. & 11. & 306 & 189 & 1401 & 839 & 13535 & 8308 \\
\hline
\end{tabular}

\section{COMPARISON OF PRICES OF TOOLS, MATERIALS AND WORK}

This chapter compares the economic difference for selected tools used in milling and EDM.

Milling tools for hardened material, a copy milling cutter with a diameter of $8 \mathrm{~mm}$ is used, which costs CZK 841 . The milling tool is used for milling clean until it is dull, then it must be reground.

The cost of material for electroerosive excavation Poco Graphite EDM 180 is 1,236.5 CZK / dm3. The cost of the graphite semi-finished product EDM 180 is given by the priceto-volume ratio.

Overhead hourly rates of machines:

Tajmac MCFV1680 : 370 CZK / hour

AGIE Compact 3: 374 CZK / hour

Individual hourly rates of machines are composed of depreciation of the machine, maintenance costs, overheads for auxiliary tools, energy intensity of the machine and other nonproduction costs (eg technical staff).

Labor costs CZK 174 / hour

According to the graph, you can see the price difference between the tools for milling and EDM. This parameter indicates a more advantageous use of milling technology. 


\section{Technical comparison}

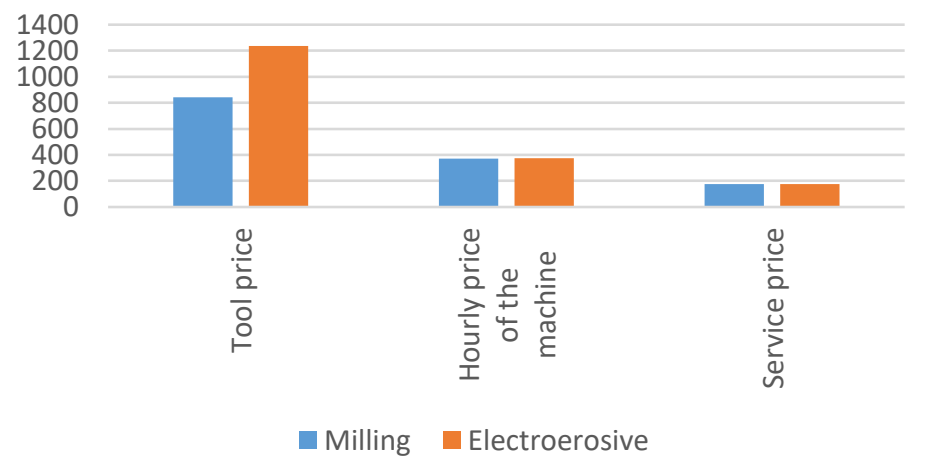

Chart 2. Technical comparison [Dostal 2012]

\section{TECHNICAL CONTRIBUTION OF THE PROPOSED SOLUTION}

In terms of the technical benefits of the proposed solution, several parameters can be mentioned that guarantee an overall improvement in production. These parameters include shortening setup and production times, using one machine for multiple operations, saving production capacity for another production, or reducing post-operation controls. As other advantages, I can mention the reduction of handling paths and operations between individual workplaces. [Dostal 2012]

According to the proposed technological procedure, the times saved by changing technologies are the main advantage. For the front insert 100, the adjustment time is reduced by 47 minutes, and the production time is then reduced by 513 minutes. For the rear insert, the adjustment time has been reduced by 9 minutes due to greater demands on precise machine adjustment. This slight improvement is multiplied by the insert production time of 213 minutes. Thanks to the new technology, the 112 shaped insert achieved a 45-minute shorter adjustment time and a 274-minute shorter production time. For the design of the rear insert 112, the benefit is in the adjustment time, which has been reduced by 45 minutes. For the main machine time, the total times were even reduced by 379 minutes. The rear insert 112 has an adjustment time reduced by 9 minutes, the total production time has been reduced by 222 minutes. The front insert 132 is characterized by a more complex shape of the inlet channel and two rows of vanes, yet the adjustment times have been halved and the production time reduced by 404 minutes. The shaped back inserts proved to be problematic in the final evaluation, when the differences are sometimes insignificant, but even these changes should be discussed. For the rear insert 132, the problem is not in the time saved, but rather in the new total price. The setup time for the new technology is 105 minutes shorter, the total machine time has been reduced by 471 minutes. The front insert 160 has an adjustment time shorter by 94 minutes and the processing time has been reduced by 1231 minutes. The last shaped insert 160 rear has a reduction time by 117 minutes compared to the current technology, the processing time has been reduced by 562 minutes. From these values, it is clear that reducing the time benefits the proposed solution and will help improve the technology. [Dostal 2012]

\section{ECONOMIC BENEFITS OF THE PROPOSED SOLUTION}

The technical benefit is related to the economic benefit of the proposed solution. By choosing a suitable technology, in addition to reducing production times, the cost of manufacturing the shaped insert will also be reduced. To calculate the new price of the insert, I used the existing calculation, which has the same value for some operations. The price calculation is different for each operation, the amount per minute is determined. An example is a mechanical operation, where according to the calculation for 30 minutes of processing, the price is CZK 90.75. Thanks to the reduction in the number of operations and the use of selected machines, the price of some inserts has been reduced by several hundred crowns: The shaped front insert 100, thanks to the proposed technology, will save CZK 4,425; the 100 back insert saves costs by CZK 2,053. Here it can be seen that the cost reduction for the rear inserts is not as great as for the front inserts. Other axle heights have reduced costs: 112 front by 1246 CZK; 112 rear by 251 CZK; 132 front by 5100 CZK; 132 rear, on the other hand, this insert has an increase in costs by CZK 100, but a reduction in production times by 8 hours; insert 160 front by 9168 CZK; 160 rear by 5227 CZK less compared to the old technology. To calculate the individual inserts, $20-30 \%$ of the times due to losses were added to each operation. [Dostal 2012]

\section{CONCLUSION}

The purpose of this project was to design a new technological process for the production of shaped inserts 100-160. The main goal was to analyze the existing technology, design a new technology, compare the two technologies, evaluate the technical and economic benefits of the proposed solution and draw conclusions for implementation in practice. When designing technological processes, it turned out that the most appropriate way would be to reduce the number of operations, which will be replaced by one technology using one machine. Examples include grinding, turning, and EDM operations, which have been replaced by milling operations on a TAJMAC machine. These changes result in a reduction in production and time costs for individual types of inserts. The total time saving for all shaped inserts $100-160$ is 3995 minutes, the highest time saving was achieved with the rear insert 112 . When calculating production costs, the total savings for all inserts $100-160$ equals the amount of CZK 27372. The savings were in thousands of most inserts, only the front 112 insert went into negative values by CZK 100. However, this loss was offset by lower production and adjustment time. The goal of this project was to design a new technological procedure. The acquired knowledge was used for the production of shaped inserts in new series.

\section{ACKNOWLEDGEMENTS}

Article has been done in connection with projects Students Grant Competition SP2021/100 financed by the Ministry of Education, Youth and Sports and Faculty of Mechanical Engineering VSB-TUO and by project MPO TRIO "FV40115 Development of a new series of medium-pressure valves, their manufacturing technology and testing methodology, simulating 60 years of service life" financed by the Ministry of Industry and trade, Czech Republic.

\section{REFERENCES}

[Alam] ALAM, M.R., K.S. LEE, M. RAHMAN, Y.F. ZHANG, Y.D. LI a K.S. SANKARAN. COMPARATIVE STUDY OF HSM AND EDM IN INJECTION MOULD MANUFACTURING. Initiatives of Precision Engineering at the Beginning of a Millennium. Boston: Springer, 324-328. DOI: https://doi.org/10.1007/0-306-47000-4 63. ISSN 978-0-306-47000-4 
[Dostal 2012] DOSTAL, P. Rationalization of Shaped Setting Block Production for Moulding Rotors AH100-160: Master Thesis. Ostrava: VSB - Technical University of Ostrava, Faculty of Mechanical Engineering, Department of machining, assembly and engineering metrology, 2016, 71 p. Thesis head: Sadilek, M.

[Grov 2005] Grov, N.: Aluminum die casting options - use of this technology in the boundary region. Foundry No. 2-3, 2005, pp. 95-101

[Havranek 2010] HAVRANEK, Radek (ed.). General technological procedures of shaped inserts from Siemens s.r.o. Mohelnice, 2010.

[Lentus 2007] 19 552.3. In: Lentus [online]. Dolni Bousov: LENTUS spol. s r.o., 2007 [cit. 2016-04-14]. Available from: http://www.lentus-ocel.cz/tridy-oceli/n-19-5523.htm

[Oettle 2005] OETTLE, Matthias. Hard milling in tool and molds. MM: Industrial spectrum. 2005, p. 30.

\section{CONTACTS}

Ing. Pavel Dostal

prof. Ing. Marek Sadilek, Ph.D.

VSB-TU Ostrava

Faculty of Mechanical Engineering

Department of machining, assembly and engineering metrology

dostal.pa@email.cz; www.vsb.cz

marek.sadilek@vsb.cz; www.vsb.cz
[Svoboda 2016] Center lathe. In: Stroje Svoboda s.r.o. [online]. Blansko: strojesvoboda.cz, 2016 [cit. 2016-03-18]. Available from:

http://strojesvoboda.cz/katalog.php?page=DETAIL\&katalog=Str oje $/$ Soustruh $\&$ key $=\& i d=9344 \& i d s=9360 \& o=1$

[TAJMAC-ZPS 2012] MCFV 1260 Vertical machining center. TAJMAC-ZPS, a.s. [online]. Malenovice: TAJMAC-ZPS, a.s., 2012 [cit. 2016-04-01]. Available from: http://www.tajmaczps.cz/en/MCFV-1260

[Tajmac-zps 2012] Tajmac-zps, mcfv 1060. TAJMAC-ZPS, a.s. [online]. Copyright (c) 2012 [cit. 2012-05-03]. Available from: http://www.tajmac-zps.cz/sites/tajmaczps2.0s.zps/files/mcfv1060 cz.pdf

[Zelinski 2000] ZELINSKI, Peter. EDM vs. Milling In Die/Mold Machining. Modern Machine Shop [online]. 2000 [cit. 2018-07-

24]. Available from:

https://www.mmsonline.com/articles/edm-vs-milling-indiemold-machining 